\title{
EFFECTS OF ISENTROPIC EFFICIENCY AND ENHANCING STRATEGIES ON GAS TURBINE PERFORMANCE
}

\author{
Thamir K. Ibrahim ${ }^{1,3}$ and M.M. Rahman ${ }^{1,2}$ \\ ${ }^{1}$ Faculty of Mechanical Engineering, Universiti Malaysia Pahang, \\ 26600 Pekan, Pahang, Malaysia. \\ E-mail: mustafizur@ump.edu.my \\ ${ }^{2}$ Automotive Engineering Centre, Universiti Malaysia Pahang, \\ 26600 Pekan, Pahang, Malaysia. \\ ${ }^{3}$ Department of Mechanical Engineering \\ College of Engineering, University of Tikrit, Tikrit, Iraq
}

\begin{abstract}
Owing to their numerous advantages, gas turbine (GT) power plants have become an important technology for power generation. This paper presents a parametric analysis for different configurations of GT plants, considering the effects of isentropic compressor and turbine efficiency, which allows the selection of the optimum GT configuration for the optimum performance of a GT power plant. The computational model was developed utilizing MATLAB software. The simulated results show that the reheat GT configuration has higher power output, whereas the regenerative GT configuration has higher thermal efficiency, when considering the effects of isentropic compressor and turbine efficiency. The maximum thermal efficiency of $52.4 \%$ and the maximum power output of $268 \mathrm{MW}$ are obtained with isentropic turbine efficiency. The result reveals that isentropic compressor and turbine efficiency influence significantly the performance of GTs.
\end{abstract}

Keywords: Gas turbine; thermodynamic; configurations; strategy; isentropic efficiency.

\section{INTRODUCTION}

Many industrial power plants are dependent on industrial gas turbines (GTs) as their means of power generation. These are referred to as GT power plants. The industries need electricity for powering their equipment, such as compressors and pumps (Basrawi, Yamada, Nakanishi, \& Naing, 2011; Ibrahim \& Rahman, 2012a; Ibrahim, Rahman, \& Abdalla, 2011a). Aircraft also use GTs, but in this case, these are then referred to as the GT cycle. It is important to understand the operating conditions fully (Milstein \&Tishler, 2011), because GT plants are often required to operate under conditions that do not fulfill their ideal operating environment, especially in the deregulated market (Woudstra, Woudstra, Pirone, \& Stelt, 2010). The global market values the relationship between energy and economic growth. Various disciplines and technical abilities need to be accumulated to create an operationally competitive GT power plant with improved performance (Bertini, Felice, Pannicelli, \& Pizzuti, 2011; Ibrahim \& Rahman, 2012b,c). Compressors, combustors, and turbines are the main components of a GT plant and consequently, they are an important part of its design and performance (Walsh \& Fletcher 2004). The GT is the key to industrial power production because of its distinct operational logic (Basrawi et al., 2011). A GT analysis component will analyze the thermodynamic processes, such as compression, 
combustion, and expansion. The organized thermodynamic analysis of these components is encompassed within the calculation of the performance parameters of a GT plant, such as thermal efficiency, power output, and specific fuel consumption. The Brayton cycle is used to apply these calculations (Saravanamuttoo, Rogers, Cohen, \& Straznicky, 2009). The entire GT cycle is based on the compression of air by the compressor, which is then transferred to the combustion chamber. This compressed air is then mixed with fuel to produce high-temperature flue gas (Kim \& Hwang, 2006). The power turbine, which is connected to the shaft of the generator for producing the electricity, receives this high-temperature flue gas.

There are only two methods of examining the performance of a GT plant and its elements at the beginning of the developmental stage: assess the prototypes of the entire GT energy plant, or consider its primary components. However, these techniques are very expensive to execute (Al-Hamadan \& Ebaid, 2006). Furthermore, a GT plant works on full load for a significant part of its life. Therefore, it is suggested that the pattern of its performance should be analyzed in detail prior to making it operational (Kim \& Hwang, 2006). A mathematical model is used together with computational methodology to obtain the most effective solution for increasing the performance of the plant (Tiwari, Islam, Hasan, \& Khan, 2010). Further research work is required to increase the performance of a power plant through the improvement of energy productivity and the reduction in fuel consumption. This is the root cause for the primary failure of this entire system, which needs to be addressed as efficiently as possible (Poullikkas, 2004). Those gadgets are very effective to use and have the potential for performance enhancement, improving the plant's design and energy analysis that may help in the future (Ahmadi, Dincer, \& Rosen, 2011). For this purpose, computerized mathematical modeling of a GT plant is very effective. The output of the GT plant, which comprises energy/fuel intake, thermal efficiency, and power output, are dependent upon the inlet and exit conditions of the energy plant (Farshi, Mahmoudi, \& Mosafa, 2008). The ambient conditions and changes of the pressure losses during the installation of the system are very important considerations when determining the parameters of turbine inlet temperature and compression (Mahmood \& Mahdi, 2009). There are two different methods for improving the pattern of cycle efficiency of the research and development, which are as follows:

i. Improve those factors that affect the performance and output of the GT in operational and normal conditions.

a) Work output of the gas turbine within the limit of International Standards Organization.

b) Increase the temperature of the turbine inlet.

c) Increase the compression ratio of the compressor.

d) Increase the isentropic efficiency of turbo-machinery elements.

ii. Perform modifications that are more effective in the cycle of the GT, which are two-shaft, reheated, intercooler, and regeneration.

The performances of a simple GT cycle and those of a number of advanced GT cycles and equivalent combined cycle GT cycles are extracted from the optimum efficiencies and work outputs, which were used in the thermodynamic analysis by Ilett and Lawn (2010). However, it is found that the performance of advanced combined cycle cycles is comparatively better than the performance of a simple GT cycle. Consequently, a parametric study on the effect of the isentropic compressor and turbine 
efficiency requires the management of the temperatures of the system. Thus, the aim of the present work is to develop a strategy to determine the performance of a GT power plant by utilizing the effects of isentropic compressor and turbine efficiency.

\section{MODELING OF A SIMPLE GAS TURBINE CYCLE}

GT power plants consist of four components: the compressor, the combustion chamber, the turbine, and the generator. A schematic diagram of a simple GT is shown in Figure 1(a). Air is drawn in by the compressor and delivered to the combustion chamber. The fuel is used to increase the temperature of the compressed air via a combustion process. Hot gases leaving the combustion chamber expand in the turbine, producing work and then finally, they are discharged to the atmosphere (state 1, 2, 3, and 4). The net work of the GT ( $\mathrm{W}_{\text {Gnet }}$ ) is calculated by Eq. (1) (Rahman, Ibrahim, Kadirgama, Mamat, \& Bakar, 2011a):

$$
W_{\text {Gnet }}=C_{p g} \times T I T \times \eta_{t}\left(1-\frac{1}{r_{p}^{\frac{\gamma_{g}-1}{\gamma_{g}}}}\right)-C_{p a} \times T_{1}\left(\frac{r_{p}^{\frac{\gamma_{a}-1}{\gamma_{a}}}}{\eta_{m} \eta_{c}}\right)
$$

where $T_{3}=T I T=$ turbine inlet temperature, $r_{\mathrm{p}}$ is the compression ratio, $\gamma_{a}=1.4$, $\gamma_{g}=1.33, C_{p a}$ is the specific heat of air, and $\eta_{m}$ is the mechanical efficiency of the compressor and turbine (Naradasu, Konijeti, \& Alluru, 2007).

The output power from the turbine $(P)$ is expressed as Eq. (2):

$$
P=\dot{m}_{g} \times W_{\text {Gnet }}
$$

where $\dot{m}_{g}$ is the mass flow rate of the exhaust gases through the GT, which is expressed as Eq. (3):

$$
\dot{m}_{g}=\dot{m}_{a}+\dot{m}_{f}
$$

The specific fuel consumption $(S F C)$ is determined by Eq. (4):

$$
S F C=\frac{3600 f}{W_{n e t}}
$$

The heat supplied is also expressed as Eq. (5) (Rahman et al., 2011a):

$$
Q_{a d d}=C_{p g} \times\left[T I T-T_{1} \times\left(1+\frac{r_{p}^{\frac{\gamma_{a}-1}{\gamma_{a}}}-1}{\eta_{c}}\right)\right]
$$


The GT efficiency $\left(\eta_{t h}\right)$ can be determined by Eq. (6) (Rahman, Ibrahim \& Abdalla, 2011b):

$$
\eta_{\text {th }}=\frac{W_{\text {Gnet }}}{Q_{\text {add }}}
$$

\section{CONFIGURATION OF GAS TURBINE CYCLE}

The simple GT (SGT) cycle efficiency is low compared with that of diesel and steam turbines. Many modifications have been carried out to improve GT performance and the most common are discussed in the following section.

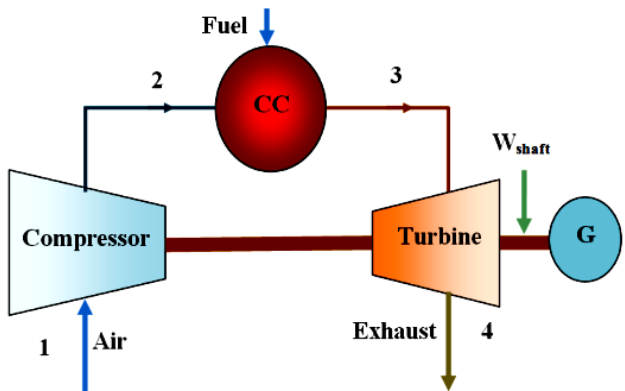

(a) SGT cycle

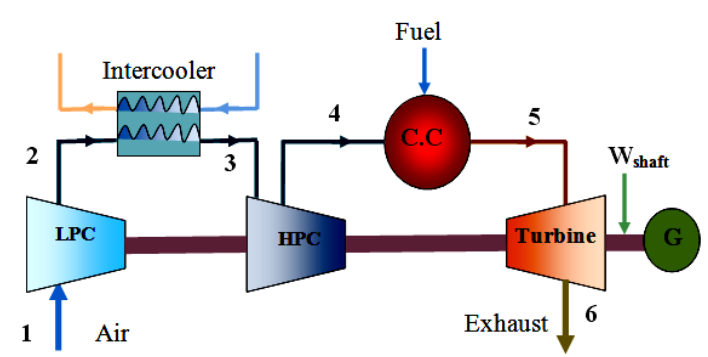

(c) IGT cycle

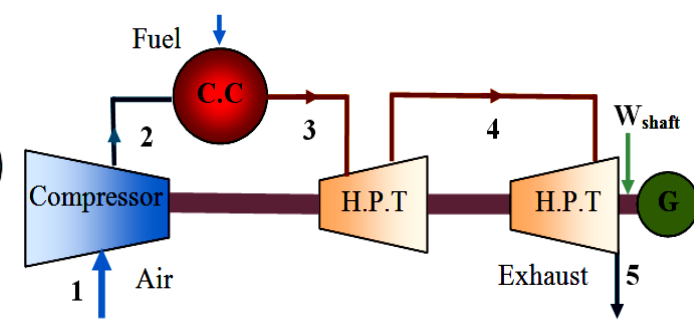

(b) TGT cycle

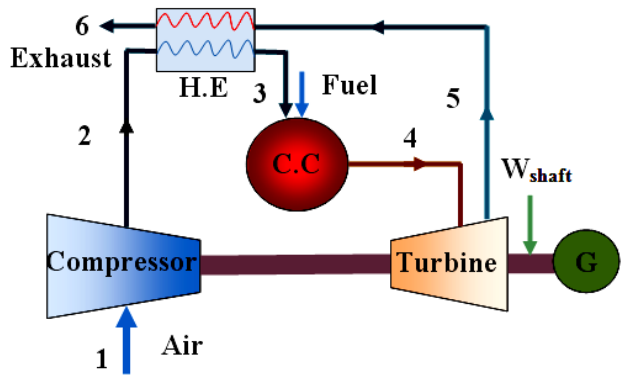

(d) RGT cycle

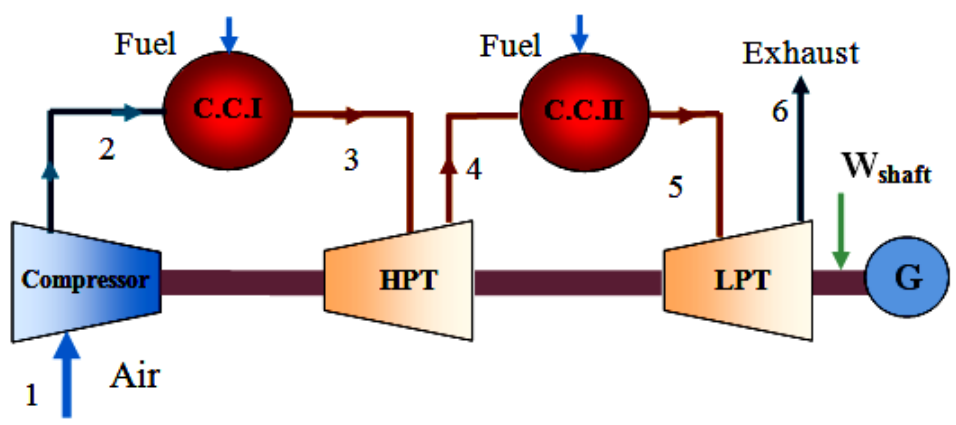

(e) HGT cycle

Figure 1. Schematic diagram of different GT cycles 


\section{Two-Shaft Gas Turbine}

The basic two-shaft GT configuration (TGT) consists of a compressor. The air is compressed adiabatically and directed to the combustion chamber where the fuel is burned with the air. The maximum cycle temperature occurs at state 3 . The exhaust gases produced by the combustion process expand adiabatically in the high-pressure turbine. Part of the developed work in the high-pressure turbine is used to drive the compressor and the remainder is delivered to drive the GT generator, as shown in Figure 1(b). The additional turbine is used to drive the GT generator (power turbine) (Cengel \& Michael, 2008). The temperature of the exhaust gases from the low pressure GT is given by Eq. (7).

$$
T_{5}=T_{4}\left[1-\eta_{t}\left(1-\frac{T_{5 s}}{T_{4}}\right)\right]
$$

where $T I T=T_{3}$ and $T_{5 s}=$ adiabatic temperature at the exit of the low-pressure turbine. The net work is expressed as Eq. (8):

$$
W_{n e t}=C_{p g}\left(T_{4}-T_{5}\right)
$$

The heat supplied is also expressed as Eq. (9):

$$
Q_{a d d}=C_{p g}\left(T I T-T_{4}\right)
$$

\section{Intercooled Gas Turbine}

Intercooling is a method to reduce the power consumption used for the compression of air. As a result, the inlet temperature of the second compressor stage can be kept low. For a given compression ratio, the power consumed in a compressor is directly proportional to the inlet temperature. Figure 1(c) shows a block diagram of a singleshaft GT plant with an intercooler (IGT). In this cycle, the air compressed in the first stage of the compressor enters an intercooler where it is cooled. The cooled air enters the second stage of the compressor, where it is compressed to the required pressure and transmitted to the combustion chamber after being heated to the maximum permissible temperature of the combustion chamber (Ibrahim, Rahman, \& Abdalla, 2010; Ibrahim, Rahman, \& Abdalla, 2011b; Rahman, Ibrahim, Taib, Noor, Kadirgama, \& Bakar, 2010). Thus, the net work output of the cycle is proportional to the temperature drop in the turbine (Ibrahim et al., 2010). The net work is expressed as Eq. (10) (Ibrahim et al., 2010):

$$
W_{\text {Gnet }}=C_{p g} \text { TIT. }\left[\frac{\eta_{t}}{\eta_{m}}\left(1-\frac{1}{\left(r_{p}^{2}\right)^{\frac{\gamma_{g}-1}{\gamma_{g}}}}\right)\right]-C_{p a} T_{1}\left(\frac{r_{p}^{\frac{\gamma_{a}-1}{\gamma_{a}}}-1}{\eta_{m} \eta_{c}}\right)\left[2+(1-x)\left(\frac{r_{p}^{\frac{\gamma_{a}-1}{\gamma_{a}}}-1}{\eta_{c}}\right)\right]
$$

In the combustion chamber, the heat supplied by the fuel is equal to the heat absorbed by the air. Hence, the heat supplied is calculated as by Eq. (11) (Ibrahim et al., 2010). 


$$
Q_{a d d}=C_{p g}\left[T I T-T_{1}+T_{2}\left(\frac{r_{p}^{\frac{\gamma_{a}-1}{\gamma_{a}}}-1}{\eta_{c}}\right)\left((2-x)+(1-x)\left(\frac{r_{p}^{\frac{\gamma_{a}-1}{\gamma_{a}}}-1}{\eta_{c}}\right)\right)\right]
$$

\section{Regenerative Gas Turbine}

The purpose of the single-shaft GT is to produce and supply the necessary power required to run the compressor for producing the net work output. In the regenerative GT (RGT) cycle, once compressed, the air enters a regenerator where it is heated by the exhaust gases from turbine, as shown in Figure 1(d). The preheated air then enters the combustion chamber, after being heated to the maximum permissible temperature of the combustion chamber (Ibrahim et al., 2011a). The net work is expressed as Eq. (12) (Rahman et al., 2010):

$$
W_{\text {Gnet }}=\frac{C_{p g} \times T I T \times \eta_{t}}{\eta_{m}}\left(1-\frac{1}{r_{p}^{\frac{\gamma_{g}-1}{\gamma_{g}}}}\right)-C_{p a} T_{1}\left(\frac{r_{p}^{\frac{\gamma_{a}-1}{\gamma_{a}}}}{\eta_{m} \eta_{c}}\right)
$$

In the combustion chamber, the heat supplied by the fuel is equal to the heat absorbed by the air, which is expressed as Eq. (13):

$$
Q_{a d d}=C_{p g} \times\left[T I T-T_{1}(1-\varepsilon) \times\left(1+\frac{r_{p}^{\frac{\gamma_{a}-1}{\gamma_{a}}}-1}{\eta_{c}}\right)-\varepsilon \times T I T \times\left[1-\eta_{t}\left(1-\frac{1}{\frac{\gamma_{g}-1}{r_{p}^{\gamma_{g}}}}\right)\right]\right]
$$

\section{Reheat Gas Turbine}

The performance of the turbine operation of the SGT cycle may be improved by reheating the gases back to the maximum cycle temperature at some intermediate point (Razak, 2007). Figure 1(e) shows a schematic diagram of a reheat GT (HGT) cycle. For the isentropic process, the work of the GT can be expressed as Eq. (14):

$$
W_{\text {Gnet }}=C_{p g}\left(T I T-T_{6}\right)
$$

where the turbine inlet temperature $(T I T)=T_{3}=T_{5}$, and $T_{4}$ is the high-pressure turbine outlet temperature.

The temperature of the exhaust gases from the low-pressure GT can be obtained by Eq. (15):

$$
T_{6}=T I T\left[1-\eta_{t}\left(1-T I T /\left(r_{p}^{\frac{\gamma_{g}-1}{\gamma_{g}}} \times T_{4}\right)\right)\right]
$$


The heat supplied for the HGT is also expressed as Eq. (16):

$$
Q_{a d d}=C_{p g}\left[\left(T I T-T_{2}\right)+\left(T I T-T_{4}\right)\right]
$$

\section{RESULTS AND DISCUSSION}

The variation of the GT exhaust temperature with isentropic compressor efficiency for different configurations is demonstrated in Figure 2. In all configurations other than RGT, at a constant turbine inlet temperature, there is no evident effect of the exhaust temperature on the isentropic compressor efficiency. This is because exhaust temperature is a function of the turbine inlet temperature (Bassily, 2012). The rise in the isentropic compressor efficiency leads to a decrease in the exhaust temperature from 780 to $631 \mathrm{~K}$ for the RGT.

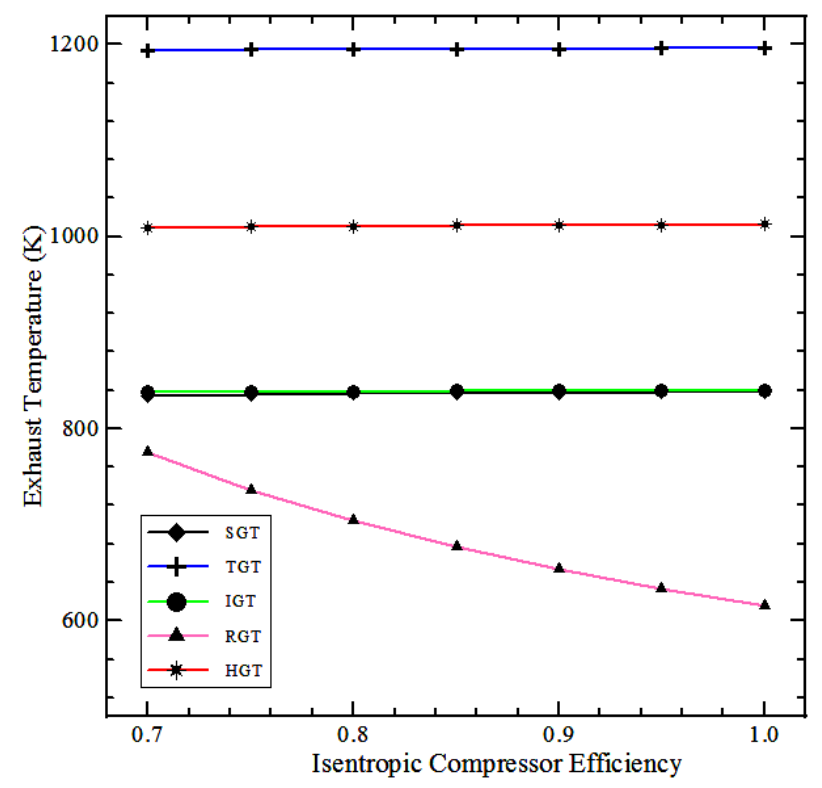

Figure 2. Effect of isentropic compressor efficiency on exhaust temperature of the GT plants.

The effect of isentropic compressor efficiencies on the thermal efficiency for different configurations of GT plants is shown in Figure 3. The increase in isentropic compressor efficiency leads to an increase in thermal efficiency. An increase in the power output is obtained because of reduced thermal losses in the compressor, which results in the increase of thermal efficiency (Godoy, Scenna, \& Benz, 2010). It is for the HGT that the lower thermal efficiency of $36.8 \%$ occurs, whereas the higher thermal efficiency of $52.3 \%$ occurs for the RGT. A noticeable deviation in thermal efficiency at higher isentropic compressor efficiency is obtained, whereas an insignificant deviation in thermal efficiency is obtained with lower isentropic compressor efficiency. The variations of the SFC and isentropic compressor efficiency for various configurations are shown in Figure 4. For all configurations, the SFC decreases with an increase of the isentropic compressor efficiency owing to decreased compressor losses (Basha, Shaahid, \& Al-Hadhrami, 2012). Therefore, there is a decrease in the fuel consumption of the GT plant. For the RGT, the lower SFC of $0.14 \mathrm{~kg} / \mathrm{kWh}$ is obtained, whereas for the HGT, a higher SFC of $0.2 \mathrm{~kg} / \mathrm{kWh}$ is obtained. The effect of isentropic compressor 
efficiency on the power output for different configurations is shown in Figure 5. In all configurations, the rise in isentropic compressor efficiency leads to an increase in the power output. This is due to the reduction in the energy losses in the compressor of the GT (Mahmood \& Mahdi, 2009). Although the lower power output (200 MW) occurs for the RGT, the higher power output of about $253 \mathrm{MW}$ occurs for the HGT.

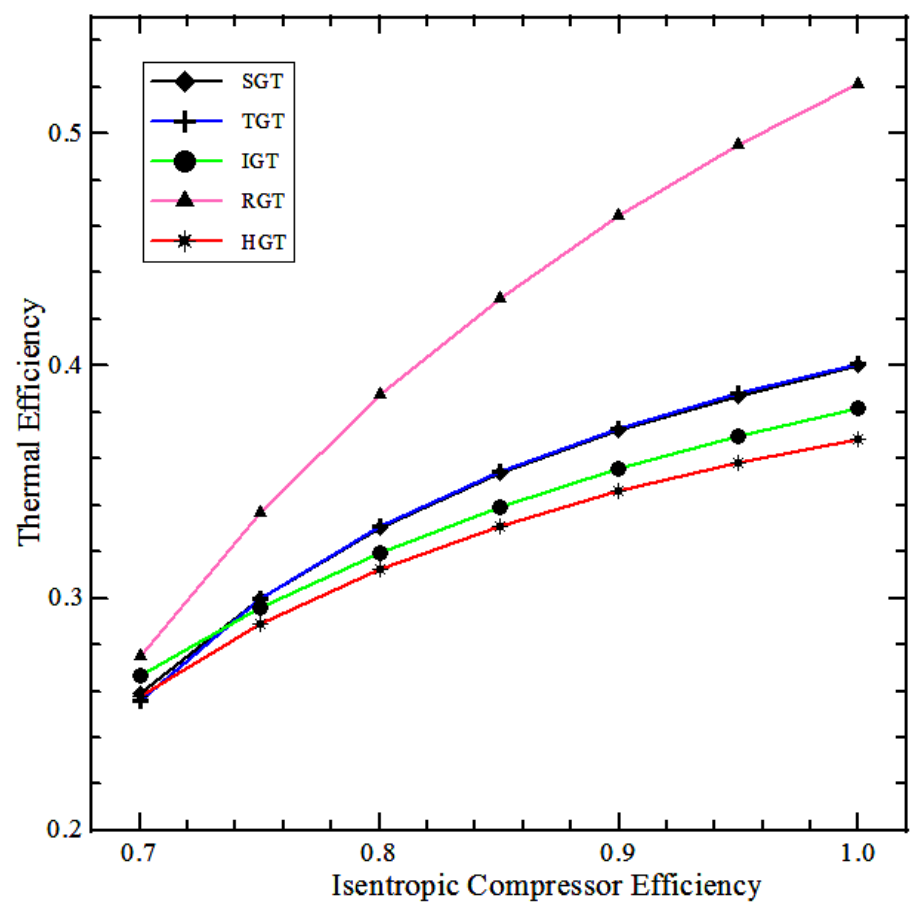

Figure 3. Effect of isentropic compressor efficiency on thermal efficiency of the GT plants.

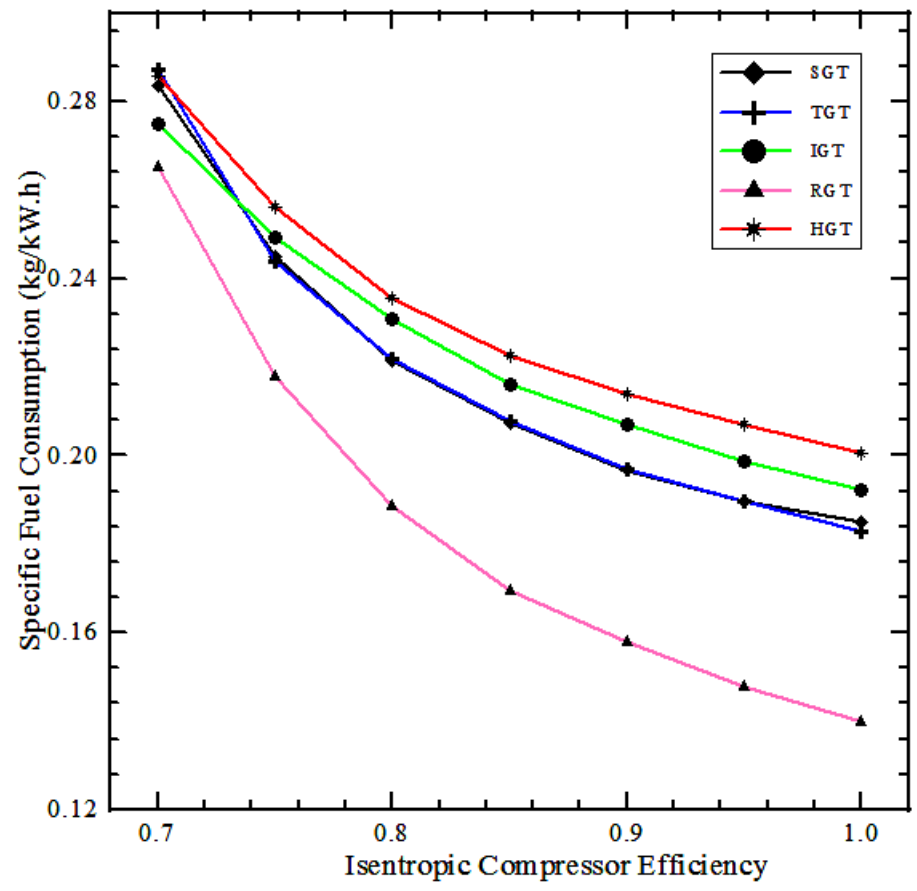

Figure 4. Effect of isentropic compressor efficiency on SFC of GT plants. 
The effect of isentropic turbine efficiency on the exhaust temperature for the different configurations is shown in Figure 6. For all configurations, the increase in isentropic turbine efficiency leads to a decrease in the exhaust temperature. This is because of the conversion of the extra heat from the exhaust gases necessary to create more useful power with the increase of the isentropic turbine efficiency (Chandraa, Aroraa, Kaushik, Tripathi, \& Rai, 2011).The two-shaft GT has the highest exhaust temperature of $1251 \mathrm{~K}$, whereas the lowest exhaust temperature of $665 \mathrm{~K}$ is obtained in the regenerative shaft. The variation of thermal efficiency against isentropic turbine efficiency of the different configurations is shown in Figure 7. There is an apparent increase in the thermal efficiency for all configurations when there is an increase in the isentropic turbine efficiency. The increased work done by the turbine of the GT plant is the reason behind this (Ameri, Ahmadi, \& Khanmohammadi, 2008). The RGT has the higher thermal efficiency of $50.8 \%$. Similar trends are observed in the thermal efficiency for other configurations of GT, but the low energy losses with the exhaust gases resulted in a higher thermal efficiency for the regenerative model. The HGT had a $39.5 \%$ low thermal efficiency. The thermal efficiency is incredibly significant at higher isentropic turbine efficiency of the GT plants.

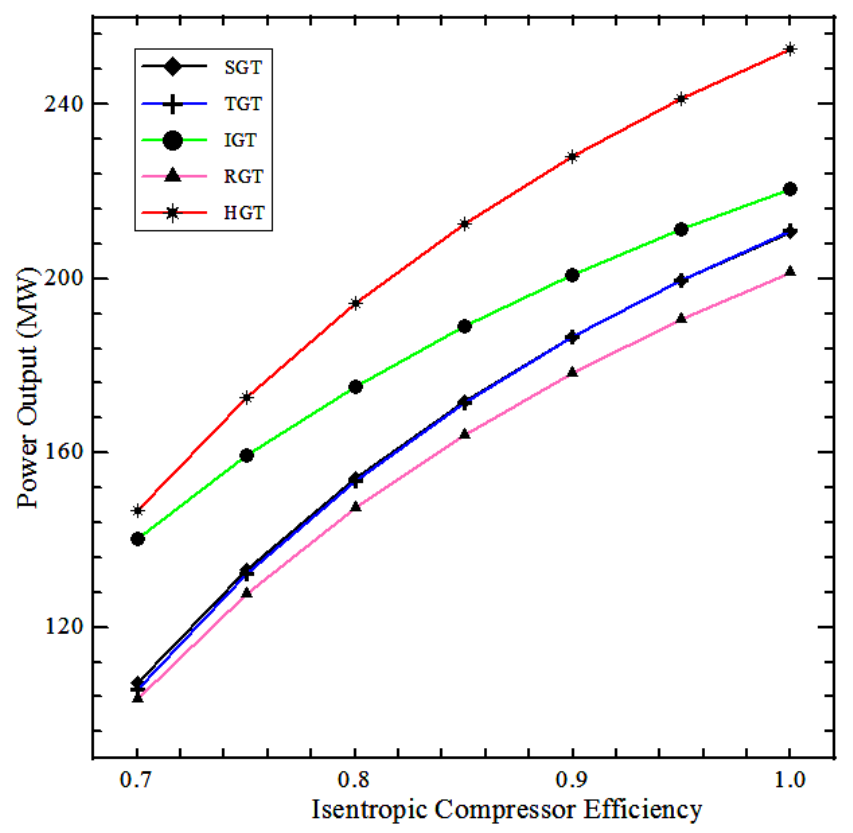

Figure 5. Effect of isentropic compressor efficiency on power output of GT plants.

The effect of isentropic turbine efficiency on SFC for different configurations is shown in Figure 8. As the isentropic turbine efficiency increases, the SFC decreases. At a constant turbine inlet temperature, the power output increases with the increase in the isentropic turbine efficiency (Godoy, Benz, \& Scenna, 2011). Therefore, under the effect of these parameters, the SFC was reduced. As more heat energy is recovered from the exhaust gases, the RGT has a lower SFC of $0.145 \mathrm{~kg} / \mathrm{kWh}$ (Kopac \& Hilalci, 2007). This leads to a reduction in the SFC of the RGT configuration. Similar behavior is observed for the other GT configurations. It was at the higher isentropic turbine efficiency that the higher SFC of $0.184 \mathrm{~kg} / \mathrm{kWh}$ was obtained in the RGT. Figure 9 shows the variation of power output in terms of isentropic turbine efficiency for the different configurations of GT. However, it is at the higher isentropic turbine efficiency 
that the power output increases linearly. The variations in power output are significant at higher isentropic turbine efficiency. As less fuel is burned in the combustion chamber of the regenerative model, a lower power output of $208 \mathrm{MW}$ is obtained in the RGT configuration. As shown in Figure 8, there is more fuel burned in the additional combustion chamber, although the higher power output (268 MW) is obtained in the HGT configuration. In the case of greater isentropic turbine efficiency of the GT plants, there is a significant power output. According to the trends of previous studies (Da Cunha Alves, De Franca Mendes Carneiro, Barbosa, Travieso, Pilidis, \& Ramsden, 2001; Kumar, 2010; Boyce, 2012), the validity of the model is emphasized through the current results.

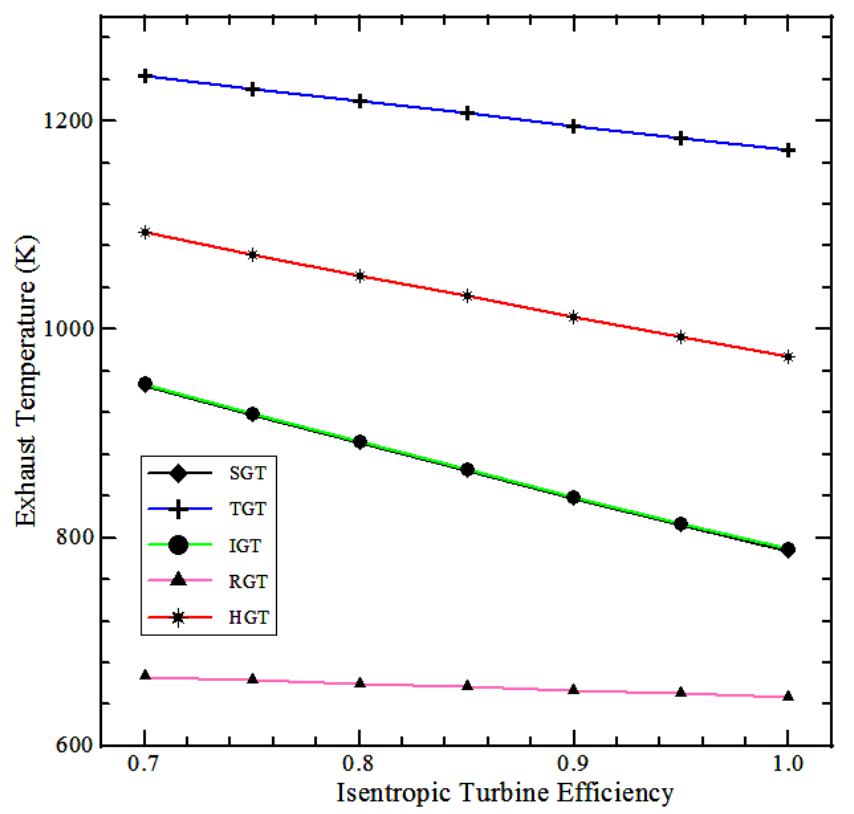

Figure 6. Effect of isentropic turbine efficiency on exhaust temperature of GT plants

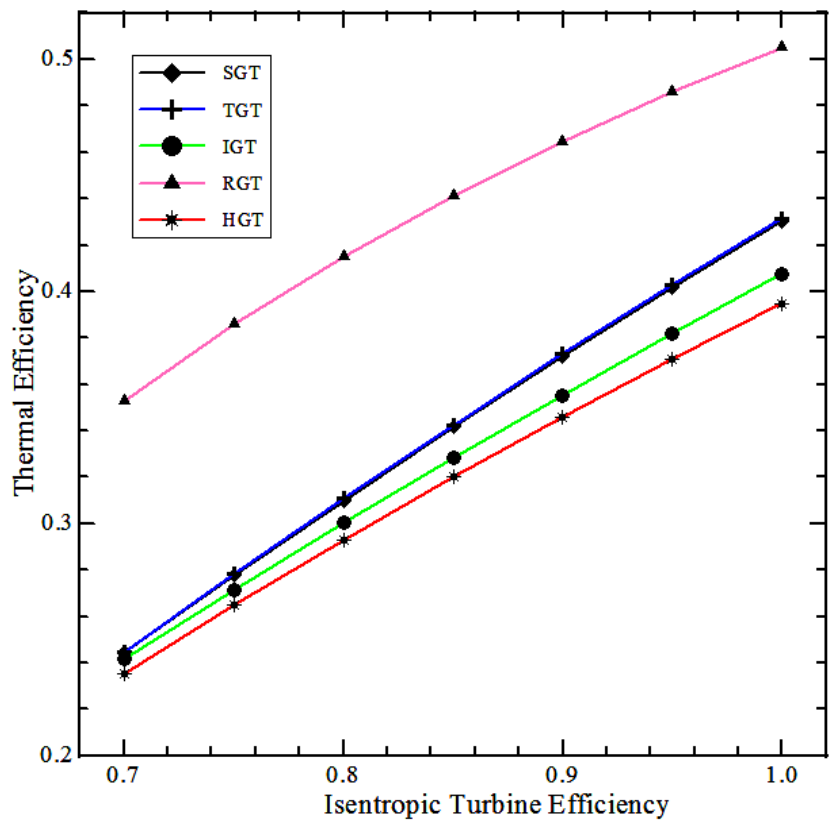

Figure 7. Effect of isentropic turbine efficiency on thermal efficiency of GT plants. 


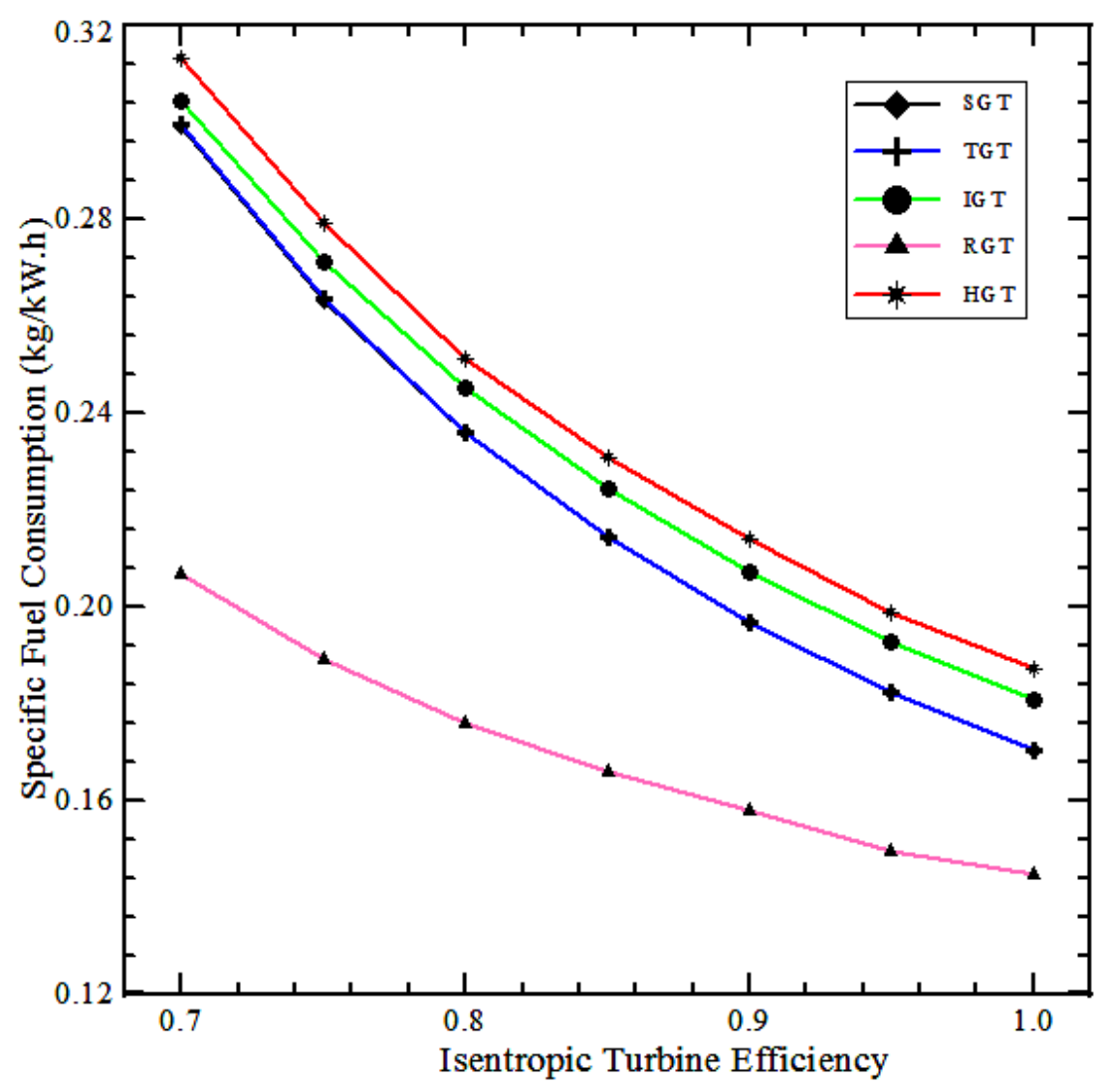

Figure 8. Effect of isentropic turbine efficiency on SFC of GT plants.

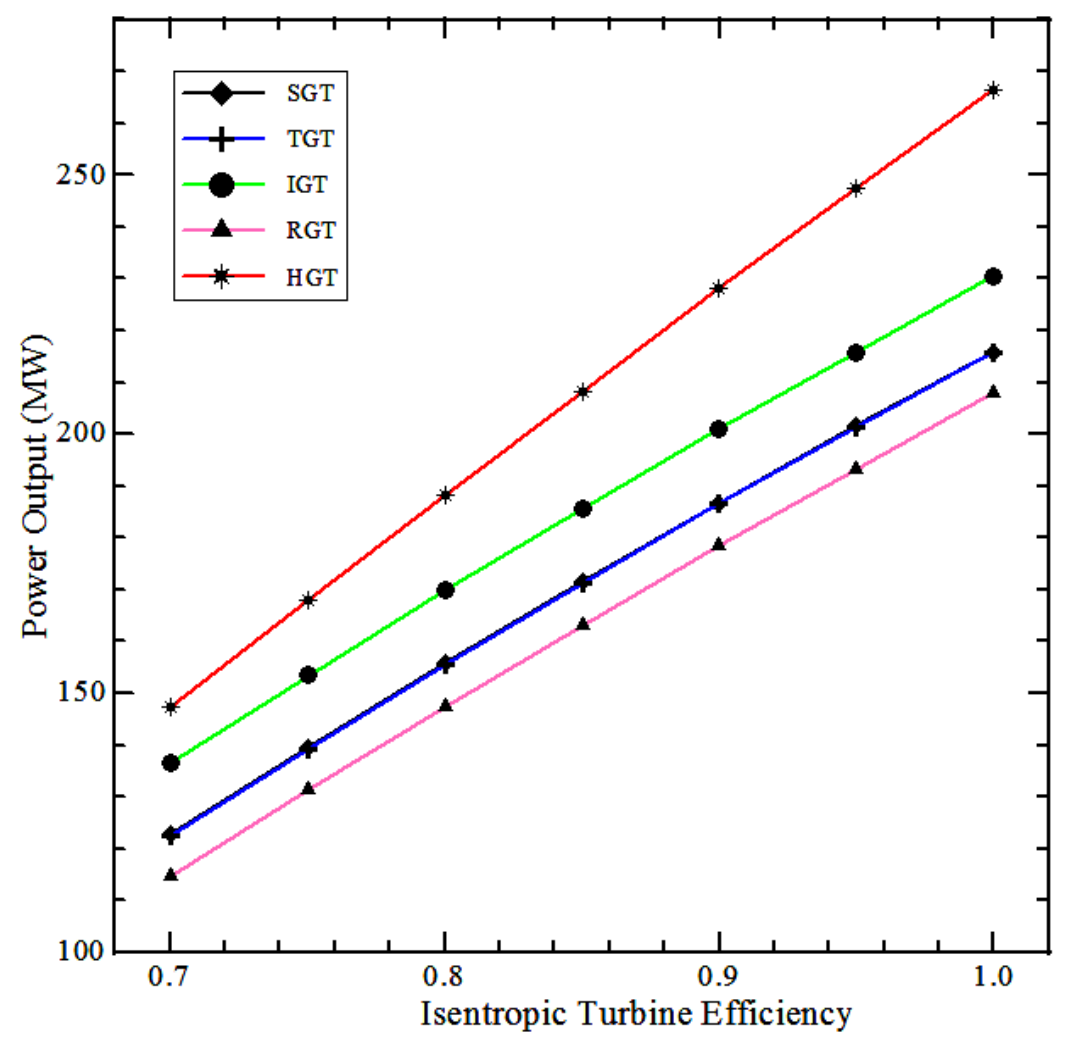

Figure 9. Effect of isentropic turbine efficiency on power output of GT plants. 


\section{CONCLUSION}

Several configurations of GT cycle have been assessed regarding the influence of isentropic compressor and turbine efficiency. The computational performance codes were developed. A parametric study of the effect of the parameters on the performance of five configurations (layouts) of the GT cycle was analyzed. The isentropic compressor and turbine efficiency have significant influence on the thermal efficiency, SFC, and power output for different configurations of GTs. The maximum power output occurred for the HGT, whereas the highest thermal efficiency was achieved by the RGT. The maximum power output and thermal efficiency occurred with the effect of isentropic turbine efficiency and the isentropic compressor efficiency. The higher power outputs are obtained in the HGT with an increase in the SFC.

\section{ACKNOWLEDGEMENTS}

The authors would like to thank the Universiti Malaysia Pahang for providing laboratory facilities and financial support under Doctoral Scholarship scheme (No. GRS100332).

\section{REFERENCES}

Ahmadi, P., Dincer, I., \& Rosen, M. A. (2011). Exergy, exergoeconomic and environmental analyses and evolutionary algorithm based multi-objective optimization of combined cycle power plants. Energy, 36(10), 5886-5898.

Al-Hamadan, Q. Z., \& Ebaid, M. S. Y. (2006). Modeling and simulation of a gas turbine engine for power generation. ASME, Journal of Engineering for Gas Turbines and Power, 128(2), 303-311.

Ameri, M., Ahmadi, P., \& Khanmohammadi, S. (2008). Exergy analysis of a 420MW combined cycle power plant. International Journal of Energy Research, 32(2), 175-183.

Basha, M., Shaahid, S. M., \& Al-Hadhrami, L. (2012). Impact of fuels on performance and efficiency of gas turbine power plants. Energy Procedia, 14, 558-565.

Basrawi, F., Yamada, T., Nakanishi, K., \& Naing, S. (2011). Effect of ambient temperature on the performance of micro gas turbine with cogeneration system in cold region. Applied Thermal Engineering, 31(6-7), 1058-1067.

Bassily, A. M. (2012). Numerical cost optimization and irreversibility analysis of the triple-pressure reheat steam-air cooled GT commercial combined cycle power plants. Applied Thermal Engineering, 40, 145-160.

Bertini, I., Felice, M. D., Pannicelli, A., \& Pizzuti, S. (2011). Soft computing based optimization of combined cycled power plant start-up operation with fitness approximation methods. Applied Soft Computing, 11(6), 4110-4116.

Boyce, M. P. (2012). Gas turbine engineering handbook. (Fourth Edition). USA: Elsevier Inc, Imprint: Butterworth-Heinemann

Cengel Y. A., \& Michael A. (2008). Thermodynamics an engineering approach. New Delhi: Tata McGraw Hill.

Chandraa, H., Aroraa, A., Kaushik, S. C., Tripathi, A., \& Rai, A. (2011). Thermodynamic analysis and parametric study of an intercooled-reheat closedcycle gas turbine on the basis of a new isentropic exponent. International Journal of Sustainable Energy, 30(2), 82-97. 
Da Cunha Alves, M. A., De Franca Mendes Carneiro, H. F., Barbosa, J. R., Travieso, L. E., Pilidis, P., \& Ramsden, K. W. (2001). An insight on intercooling and reheat gas turbine cycles. Proceedings of the Institution of Mechanical Engineers, Part A: Journal of Power and Energy, 215(2), 163-171.

Farshi, L. G., Mahmoudi, S. M. S., \& Mosafa, A. H. (2008). Improvement of simple and regenerative gas turbine using simple and ejector-absorption refrigeration. IUST International Journal of Engineering Science, 19(5-1), 127-136.

Godoy, E., Benz, S. J., \& Scenna, N. J. (2011). A strategy for the economic optimization of combined cycle gas turbine power plants by taking advantage of useful thermodynamic relationships. Applied Thermal Engineering, 31(5), 852871.

Godoy, E., Scenna, N. J., \& Benz, S. J. (2010). Families of optimal thermodynamic solutions for combined cycle gas turbine (CCGT) power plants. Applied Thermal Engineering, 30(6-7), 569-576.

Ibrahim, T. K., Rahman, M. M., \& Abdalla, A.N,. (2011a). Improvement of gas turbine performance based on inlet air cooling systems: A Technical Review. International Journal of Physical Sciences. 6(4), 620-627

Ibrahim, T. K., Rahman, M. M., \& Abdalla, A. N. (2011b). Optimum gas turbine configuration for improving the performance of combined cycle power plant. Procedia Engineering, 15, 4216-4223.

Ibrahim, T. K., Rahman, M. M., \& Abdalla, A.N. 2010. Study on the effective parameter of gas turbine model with intercooled compression process. Scientific Research and Essays, 5(23), 3760-3770.

Ibrahim, T. K., \& Rahman, M. M. (2012a). Parametric Simulation of Triple-Pressure Reheat Combined Cycle: A Case Study. Advanced Science Letters, 13, 263-268.

Ibrahim, T. K., \& Rahman, M.M. (2012b). Effect of compression ratio on performance of combined cycle gas turbine. International Journal of Energy Engineering, 2(1), 9-14.

Ibrahim, T. K., \& Rahman, M. M. (2012c). Thermal impact of operating conditions on the performance of a combined cycle gas turbine. Journal of Applied Research and Technology, 10(4), 567-577.

Ilett, T., \& Lawn, C. J. (2010). Thermodynamic and economic analysis of advanced and externally fired gas turbine cycles. Proceedings of the Institution of Mechanical Engineers, Part A: Journal of Power and Energy, 224(7),901-915.

Kim, T. S., \& Hwang, S. H. (2006). Part load performance analysis of recuperated gas turbines considering engine configuration and operation strategy. Energy, 31(23), 260-277.

Kopac, M., \& Hilalci, A. (2007). Effect of ambient temperature on the efficiency of the regenerative and reheat Çatalağzı power plant in Turkey. Applied Thermal Engineering, 27(8-9), 1377-1385.

Kumar, P. (2010). Optimization of gas turbine cycle using optimization technique. Master Thesis, Mechanical Engineering Department Thapar University Patiala147004, India.

Mahmood, F. G., \& Mahdi, D. D. (2009). A new approach for enhancing performance of a gas turbine (Case Study: Khangiran Refinery). Applied Energy, 86(12), 2750-2759.

Milstein, I., \& Tishler, A. (2011). Intermittently renewable energy, optimal capacity mix and prices in a deregulated electricity market. Energy Policy, 39(7), 3922-3927. 
Naradasu, R. K., Konijeti, R. K., \& Alluru, V. R. (2007). Thermodynamic analysis of heat recovery steam generator in combined cycle power plant. Thermal Science, 11(4), 143-156.

Poullikkas, A. (2004). Parametric study for the penetration of combined cycle technologies in to Cyprus power system. Applied Thermal Engineering, 24(1112), 1697-1707.

Rahman, M. M., Ibrahim, T. K., Kadirgama, K., Mamat, R., \& Bakar, R. A. (2011a). Influence of operation conditions and ambient temperature on performance of gas turbine power plant. Advanced Materials Research, 189-193, 3007-3013.

Rahman, M. M., Ibrahim, T. K., \& Abdalla, A. N. (2011b). Thermodynamic performance analysis of gas-turbine power-plant. International Journal of the Physical Sciences, 6(14),3539-3550.

Rahman, M. M., Thamir, K. Ibrahim, Taib, M. Y., Noor, M. M., Kadirgama, K., \& Bakar, R. A. (2010). Thermal analysis of open-cycle regenerator gas-turbine powerplants. World Academy of Science, Engineering and Technology, 68, 94-99.

Razak, A. M. Y. (2007). Industrial gas turbines performance and operability. Cambridge England: Woodhead Publishing Limited and CRC Press LLC.

Saravanamuttoo, H., Rogers, G., Cohen, H., \& Straznicky, P. (2009). Gas turbine theory. England: Pearson Prentice Hall.

Tiwari, A. K., Islam, M., Hasan, M. M., \& Khan, M. N. (2010). Thermodynamic simulation of performance of combined cycle with variation of cycle peak temperature \& specific heat ratio of working fluid. International Journal of Engineering Studies, 2(3), 307-316.

Walsh, P. P., \& Fletcher, P. (2004). Gas turbine performance. 2nd ed. USA: Blackwell Science Ltd. a Blackwell Publishing company.

Woudstra, N., Woudstra, T., Pirone, A., \& Stelt, T. (2010). Thermodynamic evaluation of combined cycle plants. Energy Conversion and Management, 51(5), 10991110 . 